\title{
Comparison of dedicated BIOSS bifurcation stents with regular drug-eluting stents for coronary artery bifurcated lesions: Pooled analysis from two randomized studies
}

Robert J. Gil ${ }^{1,2}$, Jacek Bil ${ }^{1}$, Adam Kern ${ }^{3}$, Luis A. Iñigo Garcia ${ }^{4}$, Radosław Formuszewicz ${ }^{5}$, Sławomir Dobrzycki ${ }^{6}$, Dobrin Vassilev ${ }^{7}$, Agnieszka Segiet $^{8}$

${ }^{1}$ Department of Invasive Cardiology, Central Clinical Hospital of the Ministry of Interior and Administration, Warsaw, Poland

${ }^{2}$ Mossakowski Research Science Center, Polish Academy of Science, Warsaw, Poland

${ }^{3}$ Faculty of Medical Sciences University of Varmia and Masuria, Olsztyn, Poland

${ }^{4}$ Costa del Sol Hospital, Marbella, Spain

${ }^{5} 10^{\text {th }}$ Clinical Military Hospital, Bydgoszcz, Poland

${ }^{6}$ Department of Invasive Cardiology, Medical University in Bialystok, Poland

${ }^{7}$ Alexandrovska University Hospital, Sofia, Bulgaria

${ }^{8}$ Warsaw Medical University, Warsaw, Poland

\begin{abstract}
Background: Coronary bifurcation treatment poses a therapeutic challenge. The aim of this study was to analyze pooled data of two randomized clinical trials, POLBOS I and POLBOS II, to compare 1-year follow-up results and identify possible prognostic factors.

Methods: In POLBOS trials dedicated bifurcation BiOSS ${ }^{\oplus}$ stents were compared with regular drug eluting stents ( $r D E S)$ in patients with stable coronary artery disease or non ST-segment elevation acute coronary syndrome (POLBOS I: paclitaxel eluting BiOSS ${ }^{\oplus}$ Expert vs. rDES; POLBOS II: sirolimus eluting BiOSS ${ }^{\circledast}$ LIM vs. rDES). Provisional T-stenting was the default strategy. Angiographic control was performed at 12 months. The primary endpoint was major adverse cardiovascular events (MACE) rate defined as the rate of cardiac death, myocardial infarction (MI) or target lesion revascularization (TLR).

Results: 445 patients, with 222 patients in the BiOSS group and 223 patients in the rDES group, were analyzed. In $26.7 \%$ cases procedures were performed within distal left main, and true bifurcations which accounted for $81.6 \%$ of treated lesions. At 12 months the whole population exhibited no statistical differences in terms of MACE, TLR, MI or cardiac death between rDES and BiOSS groups. In multivariate analysis odds for MACE decreased with female sex (OR 0.433, 95\% CI 0.178-0.942, $p=0.047)$ and with proximal optimization technique use (OR 0.208, 95\% CI 0.097-0.419, p < 0.001), whereas the odds for MACE increased with main vessel predilatation (OR 2.191, 95\% CI 1.042-5.066, $p=0.049)$ and diabetes mellitus treated with insulin (OR 2.779, 95\% CI 1.1-6.593, $p=0.024$ ).

Conclusions: Pooled data showed no significant difference between MACE and TLR rates for BiOSS ${ }^{\oplus}$ group vs. rDES group. (Cardiol J 2018; 25, 3: 308-316)

Key words: coronary bifurcation, drug eluting stent, proximal optimization technique, left main, diabetes mellitus
\end{abstract}

Address for correspondence: Robert J. Gil, MD, PhD, FESC, Department of Invasive Cardiology, Central Clinical Hospital of the Ministry of Interior and Administration, ul. Woloska 137, 02-507 Warszawa, Poland, tel: +48 22 508100, fax: +4822 5081177, e-mail: scorpirg@gmail.com 


\section{Introduction}

The activity of European Bifurcation Club, initiated in 2004, has led to issuing practical recommendations to improve outcomes after percutaneous treatment of coronary bifurcation lesions [1]. Recent reports have suggested that clinical outcomes after percutaneous coronary interventions (PCI) of bifurcation lesions were no longer worse than after PCI of non-bifurcation lesions or that differences were only minimal and limited to the early phase postprocedural events [2,3]. However, variety of bifurcations' anatomy induced searching for stents designed for coronary bifurcation by definition. Until that moment, big expectations associated with them have not been realized [4]. The BiOSS ${ }^{\circledast}$ dedicated coronary bifurcation stent has been extensively tested in many clinical scenarios, however, and especially important is that there are two randomized studies, POLBOS I and POLBOS II, comparing dedicated bifurcation with regular drug-eluting stents (rDES). Indeed, pooled data from those two studies allowed performing a detailed comparative analysis.

The aim of this study was to analyze pooled data of two clinical trials POLBOS I and POLBOS II in order to compare 1-year follow-up results and identify possible prognostic factors in the overall population as well as in diabetic and left main (LM) subgroups [5, 6].

\section{Methods}

\section{Study population and study design}

The POLBOS I and POLBOS II were international, multi-center, randomized, open-label, controlled trials, which are described elsewhere $[5,6]$. Briefly, the inclusion criteria were: stable coronary artery disease or non ST-segment elevation acute coronary syndrome, age $\geq 18$ years, de novo coronary bifurcation lesion (including unprotected LM stem), main vessel (MV) diameter $\geq 2.5 \mathrm{~mm}$ and side branch (SB) diameter $\geq 2.0 \mathrm{~mm}$, based on visual estimation. Main exclusion criteria were: ST-segment elevation myocardial infarction, Medina 0,0,1 bifurcations, baseline serum creatinine level $\geq 177 \mu \mathrm{mol} / \mathrm{L}(2.0 \mathrm{mg} / \mathrm{dL})$, inability to undergo dual antiplatelet therapy for 12 months, left ventricular ejection fraction $\leq 30 \%$, and the lack of informed consent. The Institutional Review Board of each participating center approved the study protocol (ClinicalTrials.gov Identifier: POLBOS I — NCT02192840, POLBOS II — NCT02198300).
Interventional procedure, device description and concomitant medication

After signing informed consent patients were randomly assigned to one of two treatment strategies: BiOSS Expert ${ }^{\circledast}$ (in POLBOS I)/BiOSS LIM ${ }^{\circledast}$ (in POLBOS II) stent implantation or rDES implantation. Patients randomized to the rDES group underwent a second randomization: completing the procedure with or without final kissing balloon technique (FKB). Provisional T-stenting was the default strategy in both treatment groups. A single stent was implanted in the MV-MB across the side branch in all patients.

The BiOSS $^{\circledast}$ is a coronary, dedicated balloonexpandable bifurcation stent. The platform is made of 316L stainless steel (strut thickness $120 \mu \mathrm{m}$ ) and the stent is coated with a biodegradable polymer that elutes paclitaxel (BiOSS ${ }^{\circledR}$ Expert - paclitaxel concentration $1 \mu \mathrm{g} / \mathrm{mm}^{2}$ ) or sirolimus (BIOSS ${ }^{\circledR}$ LIM sirolimus concentration $\left.-1.4 \mu \mathrm{g} / \mathrm{mm}^{2}\right)$. The BiOSS stent consists of two parts, proximal and distal, joined with two connection struts in the middle zone [7]. In the rDES group, use of any approved rDES available in participating cath labs was allowed. POLBOS I trial started in 2010 when paclitaxel-eluting stents (PES) were routinely used. The following regular PES were used: LucChopin2 $\left(1 \mu \mathrm{g} / \mathrm{mm}^{2}\right.$, Balton), Coroflex Please ( $1 \mu \mathrm{g} / \mathrm{mm}^{2}$, B. Braun), Taxus $(1 \mu \mathrm{g} /$ $/ \mathrm{mm}^{2}$, Eurocor) and Apollo $\left(1 \mu \mathrm{g} / \mathrm{mm}^{2}, \mathrm{IK}\right)$, whereas olimus-eluting stents (OES) were as follows: everolimus-eluting stents (Xience, Abbott Vasc; Promus, Boston Scientific), sirolimus-eluting stents (Cypher, Cordis; Prolim, Balton; Orsiro, Biotronik; Cre8, CiD), biolimus-eluting stents (Biomime, Biomime; Biomatrix, Biosensors) and zotarolimus-eluting stents (Resolute Integrity, Medtronic).

\section{Follow-up}

Clinical follow-up was performed with office visits or by telephone at 1 and 12 months after intervention. Adverse events were monitored throughout the study period. Follow-up coronary angiography was performed at 12 months unless clinically indicated in advance.

\section{Endpoints}

The primary endpoint was the cumulative rate of major adverse cardiovascular events (MACE) consisting of cardiac death, myocardial infarction (MI) and target lesion revascularization (TLR). Secondary endpoints included cardiac death, all-cause death, MI, TLR, target vessel revascularization (TVR), stent thrombosis, and device success [8]. 
Table 1. Baseline whole population clinical characteristics.

\begin{tabular}{lcccc}
\hline Parameter & Total & BiOSS group & rDES group & P \\
& $\mathbf{N}=445$ & $\mathbf{N}=222$ & 223 \\
\hline Age [years] & $66.4 \pm 9.5$ & $66.5 \pm 9.8$ & $66.4 \pm 9.20$ & 0.698 \\
Women & $126(28.3 \%)$ & $62(27.9 \%)$ & $64(28.7 \%)$ & 0.916 \\
Hypertension & $351(78.9 \%)$ & $180(81.1 \%)$ & $171(76.7 \%)$ & 0.296 \\
Hypercholesterolemia & $310(69.7 \%)$ & $160(72.1 \%)$ & $150(67.3 \%)$ & 0.303 \\
Diabetes type 2 & $153(34.4 \%)$ & $90(40.5 \%)$ & $63(28.3 \%)$ & 0.007 \\
Diabetes type 2 on insulin & $39(8.8 \%)$ & $23(10.4 \%)$ & $16(7.2 \%)$ & 0.246 \\
Prior myocardial infarction & $189(42.5 \%)$ & $99(44.6 \%)$ & $90(40.4 \%)$ & 0.389 \\
Prior PCl & $227(51 \%)$ & $112(50.5 \%)$ & $115(51.6 \%)$ & 0.85 \\
Coronary artery bypass graft & $43(9.7 \%)$ & $21(9.5 \%)$ & $22(9.9 \%)$ & 0.99 \\
Chronic kidney disease & $42(9.4 \%)$ & $23(10.4 \%)$ & $19(8.5 \%)$ & 0.521 \\
History of smoking & $104(23.4 \%)$ & $47(21.2 \%)$ & $57(25.6 \%)$ & 0.314 \\
Clinical indication for PCl: & & & $186(83.4 \%)$ \\
$\quad$ Planned PCl & $372(83.6 \%)$ & $186(83.8 \%)$ & $37(16.6 \%)$ & 0.99 \\
$\quad$ UA/NSTEMI & $73(16.4 \%)$ & $36(16.2 \%)$ & $185(83 \%)$ \\
True bifurcation & $363(81.6 \%)$ & $178(80.2 \%)$ & $38(17 \%)$ \\
False bifurcation & $82(18.4 \%)$ & $44(19.8 \%)$ & $52(27.9 \%)$ & $166(74.4 \%)$ \\
Left main bifurcation & $119(26.7 \%)$ & $160(72.1 \%)$ & 0.466 \\
Non-left main bifurcation & $326(73.3 \%)$ & & 0.594 \\
\hline
\end{tabular}

Data are shown as mean \pm standard deviation or number (percentage). $\mathrm{PCI}$ — percutaneous coronary intervention; UA/NSTEMI — unstable angina/non-ST-elevation myocardial infarction; rDES - regular drug eluting stents; BiOSS - Bifurcation Optimization Stent System Clinical Program

\section{Statistical analysis}

Continuous variables were presented as mean \pm standard deviation (SD). Categorical data were presented as numbers (\%). Continuous variables were compared using an unpaired Student two-sided $t$ test, and categorical data using the $\chi^{2}$ test or Fisher exact test, as appropriate. If distribution was not normal (verified with the Shapiro-Wilk test), Wilcoxon signed-rank tests and Mann-Whitney U-tests were used. $\mathrm{P}$ values of $<0.05$ were considered statistically significant. In further analysis univariate and multivariate logistic regression analyses were performed. The multivariate analysis was performed with AIC minimization method. Statistical analyses were performed using R 3.0.2 for OS (R Foundation, Vienna, Austria).

\section{Results}

Four hundred and forty five (445) patients, with 222 patients in BiOSS group and 223 patients in $\mathrm{rDES}$ group, were analyzed. Mean age was $66.4 \pm 9.5$ years. Baseline characteristics of the whole population is presented in Table 1 . There were no significant differences between subgroups in the whole population, apart from the diabetes rate which was higher in the BiOSS group (40.5\% vs. $28.3 \%, p=0.007)$. In $26.7 \%$ cases the procedures were performed within distal LM, and true bifurcations accounted for $81.6 \%$ treated lesions. Procedural aspects are displayed in Table 2. There were $30.5 \%$ of PES within rDES group, while in the BiOSS group - 54\%. There was a significantly higher rate of MV predilatation $(71.3 \%$ vs. $61.7 \%$, $\mathrm{p}=0.035), \mathrm{FKB}(49.3 \%$ vs. $32 \%, \mathrm{p}<0.001)$ and proximal optimization technique (POT) $(68.6 \%$ vs. $37.4 \%, \mathrm{p}<0.001)$ in the rDES group compared with the BiOSS group.

At 12 months, within the whole population, no statistical differences in terms of MACE, TLR, MI or cardiac death between rDES and BiOSS groups were observed (Fig. 1). More detailed analysis considering type of drug eluting from the stent (Table 3) showed a trend for a higher rate of MACE in PES subgroup compared with OES subgroup (19.1\% vs. $10.9 \%, p=N S$ ) in rDES group whereas in BiOSS group the difference between paclitaxel and sirolimus version was smaller $(13.3 \%$ vs. $11.8 \%$, $\mathrm{p}=\mathrm{NS}$ ). Interestingly, the same analysis for TLR rate showed the highest value in PES group, while the smallest in -olimus group ( $14.7 \%$ vs. $5.2 \%$, $\mathrm{p}=\mathrm{NS})$. In the BiOSS group TLR rate did not 
Table 2. Procedural whole population characteristics.

\begin{tabular}{lcccc}
\hline Parameter & Total & BiOSS group & rDES group & P \\
\hline Main vessel predilatation & $296(66.5 \%)$ & $137(61.7 \%)$ & $159(71.3 \%)$ & 0.035 \\
Side branch predilatation & $139(31.2 \%)$ & $74(33.3 \%)$ & $65(29.1 \%)$ & 0.358 \\
Nominal predilatation balloon diameter $[\mathrm{mm}]$ & - & $2.5 \pm 0.5$ & $2.4 \pm 0.3$ & 0.21 \\
Nominal predilatation balloon length $[\mathrm{mm}]$ & - & $13 \pm 2.1$ & $14 \pm 2.9$ & 0.19 \\
Predilatation pressure [atm] & - & $14 \pm 2.1$ & $15 \pm 2.8$ & 0.67 \\
Nominal postdilatation balloon diameter $[\mathrm{mm}]$ & - & $3.8 \pm 0.5$ & $3.5 \pm 0.4$ & 0.11 \\
Nominal postdilatation balloon length $[\mathrm{mm}]$ & - & $8 \pm 3.1$ & $12 \pm 3.4$ & 0.07 \\
Postdilatation pressure [atm] & - & $18 \pm 3.4$ & $19 \pm 3.1$ & 0.17 \\
Nominal stent diameter [mm] & - & - & $3.3 \pm 0.5$ \\
Nominal stent diameter in main vessel $[\mathrm{mm}]$ & - & $3.7 \pm 0.4$ & - \\
Nominal stent diameter in main branch $[\mathrm{mm}]$ & - & $3.0 \pm 0.4$ & - \\
Nominal stent length [mm] & - & $17.6 \pm 2.6$ & $20.3 \pm 6.6$ \\
Drug-eluting stent type: & & & 0.08 \\
$\quad$-olimus eluting & - & - & $155(69.5 \%)$ \\
$\quad$ paclitaxel eluting & - & - & $68(30.5 \%)$ \\
Proximal optimization technique & $236(53 \%)$ & $83(37.4 \%)$ & $153(68.6 \%)$ \\
Final kissing balloon & $181(40.7 \%)$ & $71(32 \%)$ & $110(49.3 \%)$ & $<0.001$ \\
Additional stent in side branch & $37(8.3 \%)$ & $22(9.9 \%)$ & $15(6.7 \%)$ & 0.235 \\
\hline
\end{tabular}

Data are shown as mean \pm standard deviation or number (percentage). rDES — regular drug eluting stents; BiOSS — Bifurcation Optimization Stent System Clinical Program

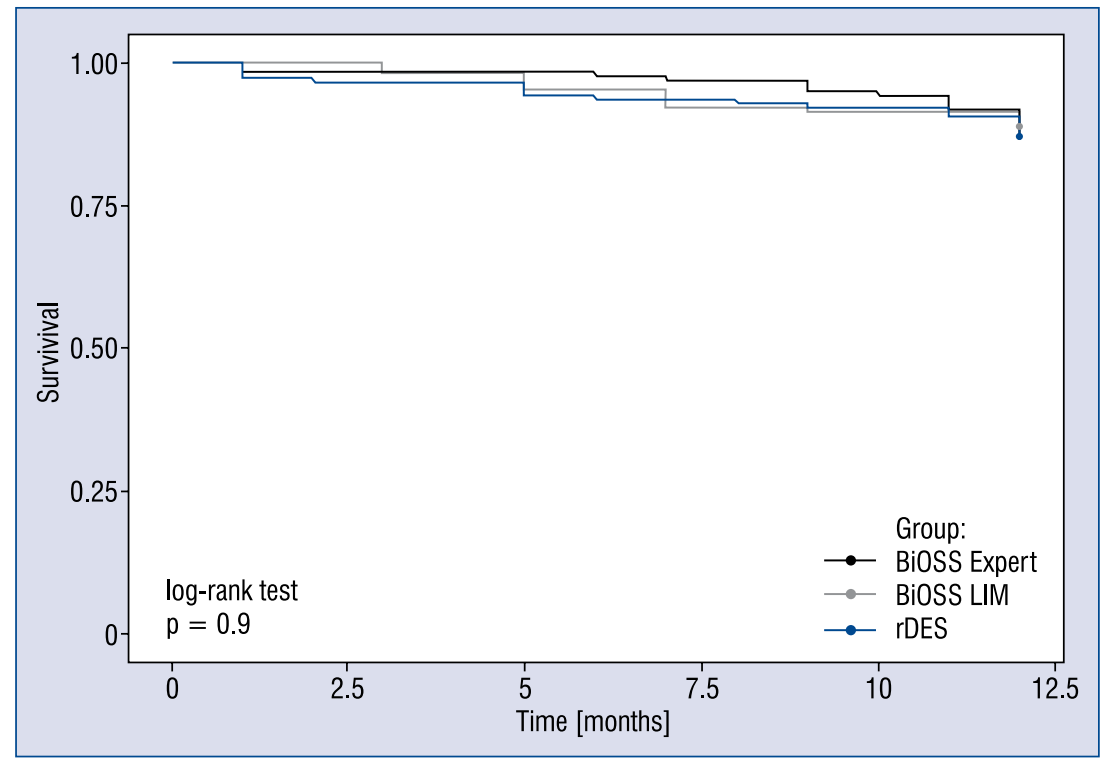

Figure 1. Kaplan-Meier curves for major adverse cardiovascular events in the whole population.

differ significantly between paclitaxel and -olimus versions ( $11.7 \%$ vs. $9.8 \%$, respectively).

When taking into consideration diabetes mellitus (DM), there was no difference in BiOSS group in terms of MACE in DM and non-DM groups (12.2\% vs. $12.9 \%, p=N S)$, whereas in rDES group pres- ence of DM mattered (20.6\% vs. $10.6 \%, \mathrm{p}=0.02$, respectively DM vs. non-DM groups) (Table 4). The same analysis showed a maintenance of such a relation for TLR rate. This parameter was significantly higher for DM population treated with rDES $(14.3 \%$ vs. $5.6 \%, \mathrm{p}=0.03)$ and did not dif- 
Table 3. Twelve-month clinical results depending of the stent type used (whole population).

\begin{tabular}{|c|c|c|c|c|c|c|}
\hline Parameter & $\begin{array}{c}\text { Total } \\
N=445\end{array}$ & $\begin{array}{c}\text { BiOSS Expert } \\
N=120\end{array}$ & $\begin{array}{c}\text { BiOSS LIM } \\
N=102\end{array}$ & $\begin{array}{c}\text { DES limus } \\
N=155\end{array}$ & $\begin{array}{c}\text { DES PES } \\
N=68\end{array}$ & $\mathbf{P}$ \\
\hline MACE & $58(13 \%)$ & $16(13.3 \%)$ & $12(11.8 \%)$ & $17(10.9 \%)$ & $13(19.1 \%)^{*}$ & 0.277 \\
\hline Death & $9(2 \%)$ & $2(1.7 \%)$ & $1(1.0 \%)$ & $4(2.6 \%)$ & $2(2.9 \%)$ & 0.78 \\
\hline MI & $11(2.5 \%)$ & $2(1.7 \%)$ & $2(2.0 \%)$ & $5(3.2 \%)$ & $2(2.9 \%)$ & 0.84 \\
\hline TLR & $42(9.4 \%)$ & $14(11.7 \%)$ & $10(9.8 \%)$ & $8(5.2 \%)$ & $10(14.7 \%)^{*}$ & 0.08 \\
\hline
\end{tabular}

*DES limus vs. DES PES; DES — drug eluting stent; MACE — major adverse cardiovascular event; MI — myocardial infarction; PES — paclitaxel eluting stent; TLR - target lesion revascularization

Table 4. Clinical results - DM vs. non-DM population.

\begin{tabular}{|c|c|c|c|c|c|c|}
\hline & \multicolumn{3}{|c|}{ DM } & \multicolumn{3}{|c|}{ Non-DM } \\
\hline & $\begin{array}{c}\text { Total } \\
153(34.4 \%)\end{array}$ & $\begin{array}{c}\text { DES } \\
N=63\end{array}$ & $\begin{array}{l}\text { BiOSS } \\
N=90\end{array}$ & $\begin{array}{c}\text { Total } \\
292(65.6 \%)\end{array}$ & $\begin{array}{c}\text { DES } \\
N=160\end{array}$ & $\begin{array}{c}\text { BiOSS } \\
N=132\end{array}$ \\
\hline MACE & $24(15.7 \%)$ & $13(20.6 \%)$ & $11(12.2 \%)^{0.067}$ & $34(11.6 \%)$ & $17(10.6 \%)^{*}$ & 17 (12.9\%) \\
\hline $\mathrm{MI}$ & $4(2.6 \%)$ & $1(1.6 \%)$ & $3(3.3 \%)$ & $7(2.4 \%)$ & $6(3.8 \%)$ & $1(0.8 \%)$ \\
\hline Death & $4(2.6 \%)$ & $3(4.8 \%)$ & $1(1.1 \%)$ & $5(1.7 \%)$ & $3(1.9 \%)$ & $2(1.5 \%)$ \\
\hline TLR & $17(11.1 \%)$ & $9(14.3 \%)$ & $8(8.9 \%)^{0.309}$ & $25(8.6 \%)$ & $9(5.6 \%)^{*}$ & $16(12.1 \%)^{0.059}$ \\
\hline
\end{tabular}

Total DM vs total non-DM = NS; *DES DM vs. DES non-DM; \#BiOSS DM vs. BiOSS non-DM = NS; DES — drug eluting stent; DM — diabetes mellitus; MACE - major adverse cardiovascular event; $\mathrm{MI}$ - myocardial infarction; TLR - target lesion revascularization

Table 5. Clinical results - LM vs. non-LM population.

\begin{tabular}{|c|c|c|c|c|c|c|}
\hline & \multicolumn{3}{|c|}{ LM } & \multicolumn{3}{|c|}{ Non-LM } \\
\hline & $\begin{array}{c}\text { Total } \\
119(26.7 \%)\end{array}$ & $\begin{array}{c}\text { DES } \\
N=57\end{array}$ & $\begin{array}{l}\text { BiOSS } \\
N=62\end{array}$ & $\begin{array}{c}\text { Total } \\
326(73.3 \%)\end{array}$ & $\begin{array}{c}\text { DES } \\
N=166\end{array}$ & $\begin{array}{c}\text { BiOSS } \\
N=160\end{array}$ \\
\hline MACE & $14(11.8 \%)$ & $9(15.8 \%)$ & $5(8.1 \%)$ & $44(13.5 \%)$ & $21(12.7 \%)$ & $23(14.4 \%)$ \\
\hline MI & $2(1.7 \%)$ & $2(3.5 \%)$ & $0(0 \%)$ & $9(2.8 \%)$ & $5(3 \%)$ & $4(2.5 \%)$ \\
\hline Death & $2(1.7 \%)$ & $2(3.5 \%)$ & $0(0 \%)$ & $7(2.1 \%)$ & $4(2.4 \%)$ & $3(1.9 \%)$ \\
\hline TLR & $11(9.2 \%)$ & $6(10.5 \%)$ & $5(8.1 \%)$ & $31(9.5 \%)$ & $12(7.2 \%)$ & $19(11.9 \%)^{0.187}$ \\
\hline
\end{tabular}

Total LM vs. total non-LM = NS; DES — drug eluting stent; LM — left main; MACE — major adverse cardiovascular event; MI — myocardial infarction; TLR - target lesion revascularization

fer significantly within the BiOSS group (8.9\% vs. $12.1 \%$, respectively DM vs. non-DM).

Also, the analysis considering division into LM and non-LM bifurcation location in treated patient showed very interesting data (Table 5 ). First of all MACE rate was the smallest in LM patients treated with BiOSS stent ( $8.1 \%$ vs. $15.8 \%$, respectively BiOSS vs. rDES group) and moreover this value was lower than in non-LM group (14.4\% vs. $12.7 \%$, respectively BiOSS vs. rDES group).

Further, in order to determine prognostic factors for coronary bifurcation treatment with dedicated bifurcation stent $\mathrm{BiOSS}^{\circledR}$ and rDES univariate and multivariate regression analyses were performed. In multivariate analysis the odds for MACE (Table 6) decreased with female sex and with POT use, whereas the odds for MACE increased with DM treated with insulin and with MV predilatation. When performing regression analyses separately in BiOSS and rDES subgroups, no significant differences from a mechanistic point of view were observed. In both subgroups POT played a key role (data not shown).

Additionally, in multivariate analysis, it was found that the odds for MACE in DM population decreased for $\mathrm{BiOSS}^{\circledR}$ stent implantation (OR 
Table 6. Logistic regression for major adverse cardiovascular events in the whole population.

\begin{tabular}{|c|c|c|c|c|}
\hline \multirow[t]{2}{*}{ Variate } & \multicolumn{2}{|c|}{ Univariate analysis } & \multicolumn{2}{|c|}{ Multivariate analysis } \\
\hline & OR $(95 \% \mathrm{CI})$ & $\mathbf{P}$ & OR (95\% CI) & $\mathbf{P}$ \\
\hline Group: BiOSS vs. DES & $0.918(0.507-1.657)$ & 0.777 & & \\
\hline Group: BiOSS Expert vs. DES & $1.001(0.490-1.971)$ & 0.998 & & \\
\hline Group: BiOSS LIM vs. DES & $0.824(0.365-1.730)$ & 0.621 & & \\
\hline Sex: female vs. male & $0.447(0.190-0.933)$ & 0.045 & $0.433(0.178-0.942)$ & 0.047 \\
\hline Age [increase per 1 year] & $0.994(0.964-1.026)$ & 0.708 & & \\
\hline NSTEMI/UA & $2.490(1.250-4.776)$ & 0.007 & $1.901(0.913-3.810)$ & 0.076 \\
\hline Arterial hypertension & $1.461(0.695-3.462)$ & 0.349 & & \\
\hline Diabetes & $1.194(0.641-2.175)$ & 0.568 & & \\
\hline Diabetes on insulin & $2.671(1.129-5.826)$ & 0.018 & $2.779(1.100-6.593)$ & 0.024 \\
\hline Dyslipidemia & $1.018(0.545-1.985)$ & 0.956 & & \\
\hline Prior myocardial infarction & $1.287(0.710-2.324)$ & 0.402 & & \\
\hline Prior $\mathrm{PCl}$ & $0.873(0.482-1.575)$ & 0.651 & & \\
\hline Coronary artery bypass graft & $1.623(0.631-3.679)$ & 0.275 & & \\
\hline Chronic kidney disease & $0.817(0.237-2.152)$ & 0.712 & & \\
\hline Smoking & $1.318(0.661-2.502)$ & 0.413 & & \\
\hline Ture bifurcation & $2.179(0.914-6.450)$ & 0.111 & & \\
\hline Left main bifurcation & $0.931(0.493-1.848)$ & 0.831 & & \\
\hline Main vessel predilatation & $2.501(1.233-5.628)$ & 0.017 & $2.191(1.042-5.066)$ & 0.049 \\
\hline Side branch predilatation & $1.405(0.752-2.565)$ & 0.275 & & \\
\hline Side branch stenting & $1.260(0.415-3.142)$ & 0.648 & & \\
\hline Final kissing balloon & $0.801(0.427-1.460)$ & 0.476 & & \\
\hline Proximal optimization technique & $0.241(0.118-0.462)$ & 0.000 & $0.208(0.097-0.419)$ & 0.000 \\
\hline Acute lumen gain & $0.675(0.426-1.144)$ & 0.253 & $0.875(0.776-1.234)$ & 0.453 \\
\hline Late lumen gain & $1.763(1.102-2.101$ & 0.041 & 1.432 (0.987-1. 902 & 0.090 \\
\hline
\end{tabular}

$\mathrm{Cl}$ - confidence interval; $\mathrm{PCl}$ - percutaneous coronary intervention; $\mathrm{OR}$ — odds ratio; UA/NSTEMI — unstable angina/non-ST-elevation myocardial infarction

$0.175,95 \%$ CI $0.045-0.609), \mathrm{p}=0.008$ and OR $0.178,95 \%$ CI $0.048-0.598$, respectively) and with POT use (OR $0.043,95 \%$ CI $0.006-0.197$ and OR $0.057,95 \%$ CI $0.011-0.222$, respectively).

The multivariate analysis considering LM location showed that the odds for MACE significantly decreased with age (OR 0.908, 95\% CI 0.838-0.976, $\mathrm{p}=0.012$ ), whereas it significantly increased in diabetes treated with insulin (OR 20.391, 95\% CI 1.535-297.915, $\mathrm{p}=0.021$ ), smoking (OR 5.921, 95\% CI 1.566-25.650, $\mathrm{p}=0.011$ ) and MV predilatation (OR 11.557, 95\% CI 1.925-222.486, $\mathrm{p}=0.027)$.

\section{Discussion}

The main findings of this study are: 1 ) There was no statistically significant difference between total BiOSS group and total rDES group regarding combined primary endpoint (MACE) as well as with regards to secondary endpoints (death, cardiac death, MI or TLR), however numerically the worst results were observed in paclitaxel-eluting rDES subgroup, whereas there was no difference between BiOSS Expert, BIOSS LIM and -olimus-eluting rDES, 2) Sub-analysis regarding the type of the antiproliferative drug revealed that in terms of TLR rate, the best results were found in -olimus-eluting rDES subgroup while the worst in paclitaxel-eluting rDES subgroup, on the contrary there was no difference between BiOSS Expert, BIOSS LIM, 3) There was a very strong trend in favor of BiOSS stents compared to rDES stents in terms of MACE rate in the diabetic subpopulation, additionally results for total BiOSS group did not differ significantly between diabetic and non-diabetic subpopulations, 4) The analysis taking into consideration bifurcation location showed that there was a trend for better results in terms of MACE and TLR rates in the case of LM subgroup when the BiOSS stent was used, 
5) In the regression analysis POT technique had the largest influence on lowering the MACE rate, whereas MV predilatation had the largest influence on increasing the MACE rate both in BiOSS as well as in the rDES groups.

The BiOSS ${ }^{\circledast}$ (Bifurcation Optimization Stent System) Clinical Program was started in 2008. The first BiOSS $^{\circledast}$ stent was a bare metal one, but shortly after a paclitaxel-eluting version was introduced to the market - the BiOSS Expert ${ }^{\oplus}$ stent. After acceptable results of the BiOSS Expert ${ }^{\circledR}$ stent in the all-comer population [9] as well as in distal LM stenosis [10] a way for improvement was to change the paclitaxel into the -olimus drug. The sirolimus was chosen and the BiOSS LIM ${ }^{\circledast}$ stent was developed. Unfortunately, 1-year results for BiOSS $^{\circledast}$ Expert and BIOSS ${ }^{\circledast}$ LIM were quite comparable between Registries as well as for POLBOS I and POLBOS II trials. This could be explained by an initially lower concentration of sirolimus than is presently used (1.0 vs. $\left.1.4 \mu \mathrm{g} / \mathrm{mm}^{2}\right)[5,6,9,11]$. Also, the stent's design reconstructed natural relations between all three parts of bifurcation and was to play an important role as well. The lack of differences between MACE rates in case of both $\mathrm{BiOSS}^{\circledR}$ stents and -olimus-eluting rDES with simultaneous differences regarding TLR in favor of -olimus-eluting rDES might suggest a protective effect of bigger neointimal proliferation reflected by higher late lumen loss in BiOSS stents caused by relatively big strut cross-sectional area $>0.01 \mathrm{~mm}^{2}$ [12].

In our analysis TLR and MACE rates for BiOSS and rDES were $10.8 \%$ vs. $8.1 \%$ and $12.6 \%$ vs. $13.5 \%$, respectively. In the paper by Chen et al. [13], after 12-month follow-up results in paclitaxel (PES) group differed significantly with sirolimus (SES) group regarding to the rate of TLR, TVR and MACE, $12.2 \%$ vs. $3.2 \%, 14.4 \%$ vs. $4.9 \%$ and $20 \%$ vs. $10.3 \%$, respectively. Also, in a meta-analysis it was proved that when comparing with PES, SES reduced the incidence of TLR, main-branch restenosis and MACE in coronary bifurcation intervention, while the risk of stent thrombosis was similar between SES and PES groups [14]. Presently, zotarolimus (ZES) and everolimus (EES) are deemed to be the gold standard in drug-eluting stents [2, 15]. Pan et al. [16] proved that EES and SES are equally effective in the treatment of coronary bifurcation lesions (1-year MACE rate of $6.1 \%$ and $6.2 \%$, respectively), while Sgueglia et al. [17] disclosed that in the treatment of bifurcations SES is better than ZES and inferior to EES (target bifurcation failure rate: $7.9 \%, 18 \%, 3.3 \%$, respectively). It is very likely that many additional parameters such as selection of patients, protocol of intervention or indications for additional stent implantation determine the results of these mainly one-center studies. In addition, it should be stressed that, contrary to a majority of other studies, there was a very high rate of control angiography (above 90\%) in the present study there were significant increases in TLR ratio.

Interestingly, this study obtained numerically better results for BiOSS than in $\mathrm{rDES}$ subgroups in cases of patients with DM. Vascular response in patients with DM and dyslipidemia differ significantly when compared with healthy controls in terms of increased neointimal area, delayed reendothelialization, and greater, persistent vascular inflammation [18]. Nevertheless, data suggest that DM and non-DM lesions showed similar vessel response in both in-stent and reference segments, regardless of the DES type [19]. The follow-up lumen in DM patients seems to be determined primarily by the smaller lumen at postprocedure rather than exaggerated neointima within the stent or plaque proliferation at the reference segments. Here, we can see the role of BiOSS design offering bigger lumen increase and laminar flow. Also, neointimal hyperplasia persists at least up to 6 months after SES implantation, which may be partly related to an exaggerated inflammatory response within the blood vessel wall. It is suggested that direct beneficial effects of anti-diabetic and anti-inflammation medications might decrease the risk of restenosis after stenting. One may presume that the BiOSS biodegradable polymer might also play such a role [20]. Nevertheless, one must admit that results obtained in rDES subgroups in POLBOS trials in diabetic patients were relatively high in comparison to other papers (POLBOS rDES MACE 20.6\%, TLR 14.3\%; Liu et al.: MACE $13.2 \%$, TLR 7.9\%, Meelu et al.: MACE 7.4\%, TLR 3.7\%) [21, 22]. A very high rate of control angiography in the present study could be one of the explanations.

Both the results of POLBOS I and POLBOS II, as well as pooled data have shown that the BiOSS ${ }^{\circledR}$ stent acts well in distal LM stenosis [23]. There was no difference between sirolimus- and paclitaxel-eluting $\mathrm{BiOSS}^{\circledast}$ stents. This suggests that the BiOSS $^{\circledast}$ construction itself played a key role. Regression analysis suggested that the higher MV/ /MB rate the lower the odds for MACE (MACE, OR $0.87, \mathrm{p}=0.057)$. This finding supports the above mentioned hypothesis. MACE and TLR rates were higher when compared with the recent findings of EXCEL or NOBLE trials, but in other studies control angiography was mandatory and such a study 
design increases values of the abovementioned endpoints [24, 25].

In the present analysis it was found that in regression analysis female sex and POT decreased the odds for MACE, whereas MV predilatation and DM treated with insulin increased the odds for MACE. These findings are similar to other studies. In the MITO Registry the independent predictors of main branch in-stent restenosis were calcification (HR 2.284, $\mathrm{p}=0.016$ ), true-bifurcation (HR 2.331, $\mathrm{p}=0.024$ ), insulin-dependent DM (insulinDM) (HR 2.259, p = 0.048). Furthermore, POT (HR 0.548, $\mathrm{p}=0.077$ ), full LM cover approach (HR 0.605, $\mathrm{p}=0.093)$ and greater minimal lumen diameter (HR 0.611, p = 0.062) had a tendency to reduce main branch in-stent restenosis [26]. Whereas, Wihanda et al. [27] disclosed the following factors associated with in-stent restenosis: stent-type $(\mathrm{OR}=4.83,95 \%$ CI 2.51-9.30), stent length $(\mathrm{OR}=3.71,95 \%$ CI 1.99-6.90), bifurcation lesions $(\mathrm{OR}=2.43,95 \%$ CI $1.16-5.10)$, smoking $(\mathrm{OR}=2.30,95 \%$ CI 1.33-3.99), vascular diameter $(\mathrm{OR}=2.18,95 \%$ CI 1.2-3.73), hypertension (OR $=2.16,95 \% \mathrm{CI} 1.16-4.04)$ and $\mathrm{DM}(\mathrm{OR}=2.14$, 95\% CI 1.23-3.70).

Nevertheless, POT and MV predilatation issues require separate analysis. Appropriate stent apposition in the proximal MV is achieved by POT, which is performed by dilating the proximal MV stent from the proximal stent edge to just proximal to the carina, using a short oversized balloon. POT improving stent apposition facilitates SB access (with scaffolding of its ostium), reduces risk of accidental abluminal rewiring, lowers the risk of stent distortion by catheter collision and as consequence enhances luminal postprocedural flow. Thus, POT should be considered as a standard step in bifurcation treatment [28]. POT was performed two-fold more often in rDES group than in the BiOSS group due to belief in POT-like effect of BiOSS stents, and in the regression analysis it positively correlated with better clinical outcomes. This seems to attest to it, that results in BiOSS group might be improved by applying obligatory POT. POT in BiOSS might have been disclosed important since in cases of thick strut stainless steel BiOSS platform, semi-compliant delivery balloon Bottle might not be so efficient as real POT performed with a non-compliant balloon.

\section{Limitations of the study}

Although the sample size was relatively small (it is in line with similar studies found in the literature) it was based on predefined statistical considerations, and primarily affects the robustness of observations of subgroup analyses. The use of multiple stent types and drugs in the control group is also a limitation, although this aspect of the design was intended to replicate real-world clinical practice. Finally, the differences in FKB and POT strategies between the study groups might have also influenced the results.

\section{Conclusions}

There was no statistically significant difference between total BiOSS group and total rDES group regarding combined primary endpoint (MACE) as well as regarding secondary endpoints (death, cardiac death, MI or TLR), however the worst results were observed in paclitaxel-eluting rDES subgroup, whereas there was no difference between BiOSS Expert, BIOSS LIM and -olimus-eluting rDES.

Conflict of interest: Robert J. Gil - Balton consultant, Jacek Bil, Adam Kern, Luis A. Iñigo Garcia, Radosław Formuszewicz, Slawomir Dobrzycki, Dobrin Vassilev, Agnieszka Segiet - nothing to declare.

\section{References}

1. Lassen JF, Holm NR, Stankovic G, et al. Percutaneous coronary intervention for coronary bifurcation disease: consensus from the first 10 years of the European Bifurcation Club meetings. EuroIntervention. 2014; 10(5): 545-560, doi: 10.4244/EIJV10I5A97, indexed in Pubmed: 25256198.

2. Diletti R, Garcia-Garcia HM, Bourantas CV, et al. Clinical outcomes after zotarolimus and everolimus drug eluting stent implantation in coronary artery bifurcation lesions: insights from the RESOLUTE All Comers Trial. Heart. 2013; 99(17): 1267-1274, doi: 10.1136/heartjnl-2013-303778, indexed in Pubmed: 23800571.

3. Ferenc M, Kornowski R, Belardi J, et al. Three-year outcomes of percutaneous coronary intervention with next-generation zotarolimus-eluting stents for de novo coronary bifurcation lesions. J Invasive Cardiol. 2014; 26(12): 630-638, indexed in Pubmed: 25480991.

4. Kern A, Gil RJ, Bojko K, et al. The approach to coronary bifurcation treatment and its outcomes in Poland: The single center experience. Cardiol J. 2017; 24(6): 589-596, doi: 10.5603/ CJ.a2017.0057, indexed in Pubmed: 28541601.

5. Gil RJ, Bil J, Grundeken MJ, et al. Regular drug-eluting stents versus the dedicated coronary bifurcation sirolimus-eluting BiOSS LIM ${ }^{\circledR}$ stent: the randomised, multicentre, open-label, controlled POLBOS II trial. EuroIntervention. 2016; 12(11): e1404-e1412, doi: 10.4244/EIJY15M11_11, indexed in Pubmed: 26600564.

6. Gil RJ, Bil J, Džavík V, et al. Regular Drug-Eluting Stent vs Dedicated Coronary Bifurcation BiOSS Expert Stent: Multicent- 
er Open-Label Randomized Controlled POLBOS I Trial. Can J Cardiol. 2015; 31(5): 671-678, doi: 10.1016/j.cjca.2014.12.024, indexed in Pubmed: 25828372.

7. Gil RJ, Bil J, Vassilev D. Vassilev D. The BiOSS stent EuroIntervention. 2015; 11(Suppl V): V153-V154.

8. Bil J, Gil RJ, Kern A, et al. Novel sirolimus-eluting stent Prolim ${ }^{\circledR}$ with a biodegradable polymer in the all-comers population: one year clinical results with quantitative coronary angiography and optical coherence tomography analysis. BMC Cardiovasc Disord. 2015; 15: 150, doi: 10.1186/s12872-015-0139-5, indexed in Pubmed: 26573577.

9. Gil RJ, Vassilev D, Michalek A, et al. Dedicated paclitaxel-eluting bifurcation stent BiOSS $®$ (bifurcation optimisation stent system): 12-month results from a prospective registry of consecutive all-comers population. EuroIntervention. 2012; 8(3): 316-324, doi: 10.4244/EIJV8I3A50, indexed in Pubmed: 22829507.

10. Bil J, Gil RJ, Vassilev D, et al. Dedicated bifurcation paclitaxeleluting stent BiOSS Expert ${ }^{\circledR}$ in the treatment of distal left main stem stenosis. J Interv Cardiol. 2014; 27(3): 242-251, doi: 10.1111/joic.12119, indexed in Pubmed: 24708143.

11. Gil RJ, Bil J, Vassiliev D, et al. First-in-man study of dedicated bifurcation sirolimus-eluting stent: 12-month results of BiOSS LIM $®$ Registry. J Interv Cardiol. 2015; 28(1): 51-60, doi: 10.1111/joic.12180, indexed in Pubmed: 25689548.

12. Gil RJ, Bil J, Legutko J, et al. Comparative assessment of three drug eluting stents with different platforms but with the same biodegradable polymer and the drug based on quantitative coronary angiography and optical coherence tomography at 12 -month follow-up. Int J Cardiovasc Imaging. 2018; 34(3): 353-365, doi: 10.1007/s10554-017-1251-7, indexed in Pubmed: 28965166.

13. Chen SL, Mintz G, Santoso T, et al. Comparison of paclitaxal vs. sirolimus eluting stents with bio-degradable polymer for the treatment of coronary bifurcation lesions: subgroup analysis from DKCRUSH-I and DKCRUSH-II studies. Chin Med J (Engl). 2012; 125(19): 3382-3387, indexed in Pubmed: 23044292.

14. Qian J, Chen Z, Ma J, et al. Sirolimus- versus paclitaxel-eluting stents for coronary bifurcations intervention: a meta-analysis of five clinical trials. Catheter Cardiovasc Interv. 2012; 80(4): 507-513, doi: 10.1002/ccd.23392, indexed in Pubmed: 22045690.

15. Costopoulos C, Latib A, Ferrarello S, et al. First- versus secondgeneration drug-eluting stents for the treatment of coronary bifurcations. Cardiovasc Revasc Med. 2013; 14(6): 311-315, doi: 10.1016/j.carrev.2013.09.006, indexed in Pubmed: 24157311.

16. Pan M, Medina A, Suárez de Lezo J, et al. Randomized study comparing everolimus- and sirolimus-eluting stents in patients with bifurcation lesions treated by provisional side-branch stenting. Catheter Cardiovasc Interv. 2012; 80(7): 1165-1170, doi: 10.1002/ccd.24281, indexed in Pubmed: 22511299.

17. Sgueglia GA, Burzotta F, Trani C, et al. Comparative assessment of mammalian target of rapamycin inhibitor-eluting stents in the treatment of coronary artery bifurcation lesions: the CASTOR-
Bifurcation registry. Catheter Cardiovasc Interv. 2011; 77(4): 503-509, doi: 10.1002/ccd.22714, indexed in Pubmed: 20602477.

18. Llano R, Winsor-Hines D, Patel DB, et al. Vascular responses to drug-eluting and bare metal stents in diabetic/hypercholesterolemic and nonatherosclerotic porcine coronary arteries. Circ Cardiovasc Interv. 2011; 4(5): 438-446, doi: 10.1161/CIRCINTERVENTIONS.110.959957, indexed in Pubmed: 21972400.

19. Sakata K, Waseda K, Kume T, et al. Impact of diabetes mellitus on vessel response in the drug-eluting stent era: pooled volumetric intravascular ultrasound analyses. Circ Cardiovasc Interv. 2012; 5(6): 763-771, doi: 10.1161/CIRCINTERVENTIONS.111.962878, indexed in Pubmed: 23149332.

20. Zhang Qi, Lu L, Pu L, et al. Neointimal hyperplasia persists at six months after sirolimus-eluting stent implantation in diabetic porcine. Cardiovasc Diabetol. 2007; 6: 16, doi: 10.1186/14752840-6-16, indexed in Pubmed: 17550588.

21. Liu Z, Jin G, Qi Y, et al. Efficacy of one- vs. two-stent implantation for coronary bifurcation lesions in diabetic patients utilizing AIR2 as an endpoint. Int J Clin Exp Med. 2015; 8(7): 11831-11842, indexed in Pubmed: 26380025.

22. Meelu OA, Tomey MI, Sartori S, et al. Comparison of provisional 1 -stent and 2-stent strategies in diabetic patients with true bifurcation lesions: the EES bifurcation study. J Invasive Cardiol. 2014; 26(12): 619-623, indexed in Pubmed: 25480989.

23. Sibbald M, Chan W, Daly P, et al. Long-term outcome of unprotected left main stenting: a Canadian tertiary care experience. Can J Cardiol. 2014; 30(11): 1407-1414, doi: 10.1016/j. cjca.2014.05.023, indexed in Pubmed: 25442439.

24. Stone G, Sabik J, Serruys P, et al. Everolimus-Eluting stents or bypass surgery for left main coronary artery disease. $\mathrm{N}$ Engl J Med. 2016; 375(23): 2223-2235, doi: 10.1056/nejmoa1610227.

25. Mäkikallio T, Holm NR, Lindsay M, et al. Percutaneous coronary angioplasty versus coronary artery bypass grafting in treatment of unprotected left main stenosis (NOBLE): a prospective, randomised, open-label, non-inferiority trial. Lancet. 2016; 388(10061): 2743-2752, doi: 10.1016/S0140-6736(16)32052-9, indexed in Pubmed: 27810312.

26. Takagi K, Ielasi A, Basavarajaiah S, et al. The impact of main branch restenosis on long term mortality following drug-eluting stent implantation in patients with de novo unprotected distal left main bifurcation coronary lesions: the Milan and New-Tokyo (MITO) Registry. Catheter Cardiovasc Interv. 2014; 84(3): 341-348, doi: 10.1002/ccd.25178, indexed in Pubmed: 24038911.

27. Wihanda D, Alwi I, Yamin M, et al. Factors associated with instent restenosis in patients following percutaneous coronary intervention. Acta Med Indones. 2015; 47(3): 209-215, indexed in Pubmed: 26586386.

28. Lassen JF, Holm NR, Banning A, et al. Percutaneous coronary intervention for coronary bifurcation disease: 11th consensus document from the European Bifurcation Club. EuroIntervention. 2016; 12(1): 38-46, doi: 10.4244/EIJV12I1A7, indexed in Pubmed: 27173860. 